\title{
DETERMINAÇÃO DE METAIS EM BEBIDAS LÁCTEAS
}

\section{DETERMINATION OF METALS IN DAIRY DRINKS}

\section{Alecssander Azevedo dos Santos ${ }^{1}$; Pedro Gardinal Michelin ${ }^{1}$; Daniel Ângelo Macena ${ }^{1}$; Vinícius Marques Gomes ${ }^{1}$}

${ }^{1}$ Universidade do Oeste Paulista, Curso de Química Bacharelado, Presidente Prudente, São Paulo.

E-mail: viniciusmarques@unoeste.br

RESUMO - A busca por produtos mais saudáveis, inovadores e de pratica utilização, movimentou o crescimento exponencial da indústria de bebidas lácteas. Diversos alimentos possuem em sua composição aditivos para realçar cor, cheiro, textura e garantir maior durabilidade. Um rigoroso controle de qualidade para verificação de contaminantes e outras substâncias potencialmente tóxicas e cancerígenas é imprescindível para o setor. O objetivo desse trabalho foi quantificar os teores dos metais chumbo, cádmio e crômio, que apresentam maior potencial tóxico em relação à saúde, que acaba afetando de forma mais significativa o público infantil. Foi utilizado o método de digestão em forno tipo mufla. Todas as três marcas analisadas apresentaram altos teores de crômio e cádmio e ausência de chumbo. A marca A apresentou os maiores níveis desses metais, seguida pela marca C, e a marca $B$ as menores concentrações, mas todas com valores acima do estabelecido pela legislação. Portanto, todas as marcas analisadas apresentaram resultados positivos.

Palavras-chave: achocolatado; toxicidade; absorção atômica; alimentos contaminados.

ABSTRACT - The search for healthier, innovative and practical products has moved the exponential growth of the dairy industry. Various foods have in their composition additives to enhance color, smell, texture and ensure greater durability. Rigorous quality control for the detection of contaminants and other potentially toxic and carcinogenic substances is essential for the industry. The objective of this work was to quantify the levels of lead, cadmium and chromium metals, which present a higher toxic potential in relation to health, which ends up affecting the children in a more significant way. The digestion method was used in a muffle oven. All three analyzed brands showed high levels of chromium and cadmium and absence of lead. The $X$ mark showed the highest levels of these metals, followed by the $Z$ mark, and the $Y$ mark the lowest concentrations, but all with values above that established by the legislation. Therefore, all the analyzed brands presented positive results. Keywords: chocolate milk; toxicity; atomic absorption; contaminated foods.

\section{INTRODUÇÃO}

Com o avanço das técnicas e da
tecnologia em alimentos, houve uma
fundamental melhoria na qualidade de vida do

ser humano, e devido a isso, a busca produtos de alta qualidade tem aumentando devido à preocupação da sociedade com uma alimentação mais nutritiva e saudável acessíveis a toda população. Sendo assim, a química do leite 
tornou-se algo muito importante nos dias de hoje para garantir a qualidade e o desenvolvimento de produtos lácteos (DIEESE, 2014).

A população mundial está em constante demanda por produtos mais saudáveis, inovadores e de prática utilização, e a consolidação dos produtos no mercado, contribuíram para o crescimento exponencial da indústria de bebidas lácteas, fazendo com que estas ganhassem popularidade (BORGES et al., 2014).

A produção de bebida láctea vem ampliando seu mercado, principalmente com o maior nível de informação sobre a importância do cálcio, a qualidade das proteínas, o papel dos componentes bioativos e das bactérias probióticas para a saúde. O Ministério de Agricultura, Planejamento e Abastecimento (MAPA) lançou programas de incentivo à produção de leite, dentre eles estão as normativas bases para elaborar o valor por litro de leite de cada produtor em específico, criando uma tabela padrão de custo do produto para o fabricante e do preço final para o consumidor (MORAES \& BENDER, 2017).

Nos últimos anos, a mudança dos hábitos de vida da população tem tornado cada vez mais dinâmica, e o seu aumento em número e em demanda, o desenvolvimento do processo de industrialização passaram a exigir mais das fábricas químicas no que se refere à potencialização de uma manufatura alimentícia que pudesse se adaptar aos novos hábitos (ALBUQUERQUE, 2017).

A utilização de aditivos, na fabricação de alimentos, com a finalidade de melhorar suas características sensoriais, tem gerado grande discussão sobre a real importância e necessidade dessas substâncias e, principalmente, sobre seus efeitos na saúde humana. Com a utilização desses aditivos alimentícios nos mais diferentes produtos, o controle de qualidade se torna indispensável. Um dos problemas que pode estar presente é o teor elevado de metais tóxicos em sua composição, provenientes da contaminação da síntese da matéria-prima ou do processo de manufatura (SÁ et al., 2016).

Inúmeros alimentos consumidos pela população contêm aditivos como corante em sua composição, aumentando a quantidade destas substâncias ingeridas, que, em longo prazo, podem causar problemas na saúde. Mesmo um contaminante em pequena quantidade pode se tornar um potencial fator de complicações na saúde (HAMERSKI, REZENDE, SILVA, 2013).

É fundamental a existência de um rigoroso controle de qualidade para verificar os contaminantes e outras substâncias na indústria alimentícia, por causa do potencial tóxico e carcinogênico. Visando regulamentar este ponto em questão, o Conselho Nacional de Saúde aprovou a Resolução CNS/MS no. 04, na qual indica os índices de purezas e o limite máximo de contaminantes inorgânicos que podem estar contidos nos alimentos (ALBUQUERQUE, 2017).

Alguns elementos químicos essenciais são necessários para o funcionamento fisiológico normal do organismo humano, logo, é muito importante adquiri-los por meio da alimentação diária. Embora alguns metais sejam essenciais, outros podem ser prejudiciais, causando efeito de toxicidade agudo ou crônico. Esta toxicidade varia não só do metal tóxico em si, mas da sua forma e concentração, salientando-se, ainda, que a maior parte dos metais encontrados no organismo humano apresenta alta reatividade química e atividade biológica, particularmente na forma de íons, radicais ou complexos orgânicos. Podem, potencialmente, ser de alto risco, dependendo da quantidade ingerida e de outras condições, como o tempo e frequência da exposição e suscetibilidade do organismo exposto (BRANDÃO, 2016).

Este trabalho foi realizado com o intuito de quantificar os teores de Cromo, Cádmio e Chumbo presentes em bebidas lácteas em marcas selecionadas conforme o nível de popularidade e consumo, para verificar se tais concentrações se encontram dentro dos limites máximos permitidos conforme a legislação.

\section{MÉTODO}

As amostras foram adquiridas em estabelecimentos da cidade de Presidente Venceslau. A princípio, foram selecionadas três marcas ( $A, B$ e $C$ ) de bebidas lácteas e foram submetidas às análises de caráter qualitativo $e$ quantitativo de mesmos lotes, totalizando 27 amostras.

As amostras foram tratadas e analisadas pelo método conhecido como digestão em forno tipo mufla baseada na metodologia $A O A C$, já que para realizar este tipo de análise, é necessária a remoção de todos os componentes orgânicos da bebida. 
Em cadinhos de porcelana distintos, adicionou-se $20 \mathrm{~mL}$ de bebida láctea referentes a cada marca; levadas para a mufla a temperatura $550{ }^{\circ} \mathrm{C}$ elevada gradualmente, e mantida nessa temperatura por 2 horas.

Decorrido o tempo, as amostras foram retiradas do forno e deixadas na bancada para resfriar naturalmente. As cinzas residuais foram dissolvidas com $5 \mathrm{~mL}$ de ácido nítrico $\left(\mathrm{HNO}_{3}\right)$ concentrado, e o extrato lavado quantitativamente com água deionizada para balão volumétrico de $25 \mathrm{~mL}$.

Cada uma dessas soluções, fora filtrado com membrana celulósica com $0,45 \mu \mathrm{m}$ de diâmetro, sendo trocada a membrana a cada 3 amostras filtradas.

Os extratos foram transferidos para vidros âmbar, armazenados e refrigerados até a realização das análises. Todo procedimento foi realizado em 9 repetições para cada marca, segundo a metodologia de digestão em forno tipo mufla (INSTITUTO ADOLFO LUTZ, 2008).

$O$ preparo das amostras foram realizadas nos laboratórios de Química, localizados no Bloco $Q$, da Universidade do Oeste Paulista - UNOESTE de Presidente Prudente, Estado de São Paulo. E as análises realizadas por espectrometrias de absorção atômica em chama (FAAS), no laboratório de solos da Universidade do Oeste Paulista - UNOESTE de Presidente Prudente, Estado de São Paulo.

Os resultados foram comparados com os dados estipulados segundo ANVISA (2005) e MAPA (2013), onde os limites máximos de contaminantes inorgânicos devem estar abaixo de $0,10 \mathrm{mg} / \mathrm{L}$ para crômio, $0,05 \mathrm{mg} / \mathrm{L}$ para cádmio e $0,02 \mathrm{mg} / \mathrm{L}$ para chumbo.

\section{RESULTADOS}

Para as Marca A, B e C, os resultados foram apresentados nas TABELAS 1, 2 e 3 :
Tabela 1. Resultados para a Marca A ( $\mathrm{mg} / \mathrm{L}$ ).

\begin{tabular}{c|c|c|c}
\hline Amostra & {$[\mathbf{C r}]$} & {$[\mathbf{C d}]$} & {$[\mathbf{P b}]$} \\
\hline A1-1 & 19 & 0,62 & 0 \\
\hline A1-2 & 26,58 & 0,86 & 0 \\
\hline A1-3 & 5,02 & 0,26 & 0 \\
\hline A2-1 & 22,38 & 0,15 & 0 \\
\hline A2-2 & 25,77 & 0,11 & 0 \\
\hline A2-3 & 28,72 & 0 & 0 \\
\hline A3-1 & 11,85 & 0 & 0 \\
\hline A3-2 & 12,81 & 0 & 0 \\
\hline A3-3 & 10,81 & 0 & 0 \\
\hline
\end{tabular}

Fonte: próprio autor.

Tabela 2. Resultados para a Marca B (mg/L).

\begin{tabular}{c|c|c|c}
\hline Amostra & {$[\mathrm{Cr}] \mathbf{~ m g} / \mathbf{L}$} & {$[\mathrm{Cd}]$} & {$[\mathrm{Pb}]$} \\
\hline B1-1 & 12,02 & 0,11 & 0 \\
\hline B1-2 & 3,58 & 0,14 & 0 \\
\hline B1-3 & 4,61 & 0,32 & 0 \\
\hline B2-1 & 7,47 & 0,67 & 0 \\
\hline B2-2 & 12,26 & 0 & 0 \\
\hline B2-3 & 6,06 & 0,59 & 0 \\
\hline B3-1 & 7,33 & 0,25 & 0 \\
\hline B3-2 & 17,47 & 0,72 & 0 \\
\hline B3-3 & 5,78 & 1,15 & 0 \\
\hline
\end{tabular}

Fonte: próprio autor.

Tabela 3. Resultados para a Marca C (mg/L).

\begin{tabular}{c|c|c|c}
\hline Amostra & {$[\mathbf{C r}]$} & {$[\mathbf{C d}]$} & {$[\mathbf{P b}]$} \\
\hline $\mathbf{C 1 - 1}$ & 7,14 & 0 & 0 \\
\hline C1-2 & 8,22 & 0 & 0 \\
\hline C1-3 & 8,61 & 0,73 & 0 \\
\hline C2-1 & 7,22 & 0 & 0 \\
\hline C2-2 & 5,34 & 0 & 0 \\
\hline C2-3 & 16,61 & 0 & 0 \\
\hline C3-1 & 20,46 & 0 & 0 \\
\hline C3-2 & 13,17 & 0 & 0 \\
\hline C3-3 & 7,36 & 0 & 0 \\
\hline
\end{tabular}

Fonte: próprio autor.

\section{DISCUSSÃO}

Conforme a legislação dos limites máximos de contaminantes inorgânicos, e o resultados obtidos com as analises, temos a média de cada marca: 
Tabela 4. Média dos resultados ( $\mathrm{mg} / \mathrm{L}$ ).

\begin{tabular}{c|c|c|c}
\hline Amostras & {$[\mathbf{C r}]$} & {$[\mathrm{Cd}]$} & {$[\mathrm{Pb}]$} \\
\hline A1 & 16,87 & 0,58 & 0 \\
\hline A2 & 25,63 & 0,09 & 0 \\
\hline A3 & 11,83 & 0 & 0 \\
\hline Média (A) & 18,11 & 0,22 & 0 \\
\hline B1 & 6,74 & 0,19 & 0 \\
\hline B2 & 8,60 & 0,42 & 0 \\
\hline B3 & 10,20 & 0,71 & 0 \\
\hline Média (B) & 8,84 & 0,44 & 0 \\
\hline C1 & 7,99 & 0,25 & 0 \\
\hline C2 & 9,73 & 0 & 0 \\
\hline C3 & 13,67 & 0 & 0 \\
\hline Média (C) & 10,46 & 0,08 & 0 \\
\hline
\end{tabular}

Fonte: próprio autor.

Através dos resultados apresentados na TABELA 4, a marca A apresentou concentração média de $18,11 \mathrm{mg} / \mathrm{L}$ para crômio e $0,22 \mathrm{mg} / \mathrm{L}$ para cádmio.

A marca B apresentou concentração média de $8,84 \mathrm{mg} / \mathrm{L}$ para crômio e $0,44 \mathrm{mg} / \mathrm{L}$ para cádmio.

Para os produtos da marca C, o valor médio de crômio foi de $10,46 \mathrm{mg} / \mathrm{L}$ e $0,08 \mathrm{mg} / \mathrm{L}$ de cádmio, sendo o único valor mais próximo da legislação, mas ainda acima do permitido.

De acordo com os resultados, todas as marcas estão muito acima do limite máximo de contaminantes inorgânicos permitido pela legislação brasileira. A marca A foi a que se apresentou níveis mais alarmantes de crômio, $181 \%$ acima do permitido perante a legislação.

\section{CONSIDERAÇÕES FINAIS}

Conclui-se que a marca A, B e C, obtiveram valores distintos, porém, todos superiores a legislação. Após as análises e cálculos, verificou-se que não existia chumbo em nenhuma das amostras, apenas crômio e cádmio.

A marca A apresentou a maior concentração de crômio, em média $18,11 \mathrm{mg} / \mathrm{L}$. Esses resultados são muito preocupantes já que essas bebidas são muito populares e consumidas principalmente por crianças. O consumo diário desta bebida pode causar sérios problemas de saúde em longo prazo.
Já a marca B foi a que apresentou o maior teor de cádmio em sua composição. $O$ resultado obtido foi em torno de $9 \%$ acima do permitido.

Para a marca $C$, seus níveis de crômio também estão muito elevados, mas, o teor de cádmio foi o que mais se aproximou dos limites permitidos, apenas $0,03 \mathrm{mg} / \mathrm{L}$ acima.

Desta forma, conclui-se que todas as três marcas analisadas apresentaram teores elevados de crômio e cádmio, e ausência de chumbo.

\section{REFERÊNCIAS}

ALBUQUERQUE, L.G.R. Estudo de métodos para determinação total, fracionamento e análise de especiação elementar em fertilizantes base orgânica. 2017. Tese (Doutorado em Química) Instituto de Química, Universidade de São Paulo, São Paulo, 2017.

ANVISA. Agencia Nacional de Vigilância Sanitária. Resolução RDC no 272, de 22 de setembro de 2005.

BORGES, M.S. et al. Modernização, trabalho e produtividade na pequena produção leiteira na Argentina e no Brasil. Revista ADM. MADE, v. 18, n. 1, p. 12-31, 2014.

BRANDÃO, J.A.C. Teores de elementos tóxicos (As, Cd) e essenciais ( $\mathrm{Ca}, \mathrm{Fe}, \mathrm{Mg}$ e $\mathrm{Mn}$ ) em chás comercializados no Distrito Federal e a contribuição do seu consumo nos limites e/ou necessidades de ingestão diárias. Universidade de Brasília, 2016.

BRASIL. Ministério da Agricultura, Pecuária e Abastecimento - MAPA. Resolução - RDC № 42, de 29 de agosto de 2013.

DEPARTAMENTO Intersindical de Estatística e Estudos Socioeconômicos - DIEESE. Alimentos ainda pressionam o custo de vida em São Paulo. Nota à imprensa, dez. 2014.

HAMERSKI, L.; REZENDE, M. J. C.; SILVA, B.V. Usando as cores da natureza para atender aos desejos do consumidor: substâncias naturais como corantes na indústria alimentícia. Revista Virtual de Química, v. 5, n. 3, p. 394-420, 2013.

INSTITUTO ADOLFO LUTZ. Métodos físicoquímicos para análise de alimentos. Coordenadores Odair Zenebon, Neus Sadocco 
Pascuet e Paulo Tiglea. 4. ed. São Paulo: Instituto Adolfo Lutz, 2008. 1020 p. Primeira edição digital.

MORAES, B.M.M; BENDER, R. Mercado Brasileiro de Lácteos: análise do impacto de políticas de estímulo à produção. Rev. Econ. Sociol. Rural, Brasília, v. 55, n. 4, p. 783-800, Dec. 2017.

SÁ, Paula et al. Uso abusivo de aditivos alimentares e transtornos de comportamento: há uma relação?. Revista Internacional de Nutrologia, [S.I.], v. 9, n. 2, p. 209-215, sep. 2016. ISSN 1984-3011. 